\title{
CECILIA regional climate simulations for the present climate: validation and inter-comparison
}

\author{
Petr Skalák ${ }^{1,2, *}$, Michel Déqué ${ }^{3}$, Michal Belda ${ }^{4}$, Aleš Farda ${ }^{1,2}$, Tomáš Halenka ${ }^{4}$, \\ Gabriella Csima $^{5}$, Judit Bartholy ${ }^{6}$, Mihaela Caian ${ }^{7}$, Valery Spiridonov ${ }^{8}$ \\ ${ }^{1}$ Czech Hydrometeorological Institute, 14306 Prague, Czech Republic \\ ${ }^{2}$ Global Change Research Centre, Academy of Science of the Czech Republic, 60300 Brno, Czech Republic \\ ${ }^{3}$ Météo-France, Centre National de Recherches Météorologiques, 31057 Toulouse, France \\ ${ }^{4}$ Charles University in Prague, Department of Meteorology and Environment Protection, 18200 Prague, Czech Republic \\ ${ }^{5}$ Hungarian Meteorological Service, 1525 Budapest, Hungary \\ ${ }^{6}$ Eötvös Loránd University, Dept. of Meteorology, 1518 Budapest, Hungary \\ ${ }^{7}$ Rossby Centre, Swedish Meteorological and Hydrological Institute, 60176 Norrköping, Sweden \\ ${ }^{8}$ National Institute of Meteorology and Hydrology, 1784 Sofia, Bulgaria
}

\begin{abstract}
We investigated high-resolution simulations of regional climate models (RCMs) driven by ERA-40 reanalyses over areas of selected European countries (Austria, Czech Republic, Hungary, Slovakia and Romania) for the period 1961-1990. RCMs were run at a spatial resolution of $10 \mathrm{~km}$ in the framework of the CECILIA project, and their outputs were compared with the EOBS dataset of gridded observations and RCM simulations at coarser $25 \mathrm{~km}$ resolution from the ENSEMBLES project to identify a possible gain from the CECILIA experiments over ENSEMBLES. Cold biases of air temperature and wet biases of precipitation dominate in the CECILIA simulations. Spatial variability and distribution of the air temperature field are well captured. The precipitation field, relative to observations, often shows inadequately small spatial variability and lowered correlations but is nevertheless comparable to the ENSEMBLES model. Inter-annual variability (IAV) of air temperature is captured differently among seasons but mostly improved in CECILIA compared with ENSEMBLES. Precipitation IAV shows a similar or worse score. The detected weaknesses found within the validation of the CECILIA RCMs are attributed to the resolution dependence of the set of physical parameterizations in the models and the choice of integration domain. The gain obtained by using a high resolution over a small domain (as in CECILIA) relative to a lower resolution $(25 \mathrm{~km}$ ) over a larger domain (as in ENSEMBLES) is clear for air temperature but limited for precipitation.
\end{abstract}

KEY WORDS: RCM $\cdot$ Model performance $\cdot$ Validation $\cdot$ CECILIA $\cdot$ ALADIN-Climate $\cdot$ RegCM3

\section{INTRODUCTION}

Regional climate models (RCMs) are widely used tools for the assessment of regional aspects of climate change. They have emerged in the last 2 decades as an answer to an increased demand for information about climate change and its impact on a regional scale. This information cannot be obtained directly from global climate models (GCMs) because of their relatively coarse horizontal spatial resolution. Dy- namical downscaling of GCM simulations by RCMs is one of the current approaches to simulate climate conditions on a regional scale. The basis of regional modeling has been widely described since the 1990s, e.g. in Giorgi \& Mearns (1991, 1999).

The current generation of RCMs typically operates at horizontal resolutions from $\sim 50$ to $10 \mathrm{~km}$. The benefits of a finer resolution are mainly found in regions where complex topography or surface physiographic features affect the local climate. Some simulated 
properties, e.g. precipitation, are particularly sensitive to an increased resolution and a better surface description. While the dynamical part of RCMs is coded irrespective of resolution, a package of physical parameterizations can require an adaptation for a particular range of spatial scales. This has been proved during the development of RCMs (Laprise 2008). Recent studies also suggest that even if the overall quality of GCM and RCM simulations improves or at least remains unchanged with a higher model resolution (Reichler \& Kim 2008, Meissner et al. 2009), the use of a higher resolution may present some discrepancies as well.

The analysis of resolution effects on precipitation in an ensemble of RCM simulations over Europe (Rauscher et al. 2010) revealed larger precipitation amounts at a higher resolution, especially in the summer, leading to a slight increase of wet biases relative to the coarser resolution. The tendency of most RCMs to simulate more precipitation and increase wet biases in some regions and seasons under higher resolutions was also reported by other authors (e.g. Halenka et al. 2006, Bergant et al. 2007, Jaeger et al. 2008, Suklitsch et al. 2011). However, some systematic errors in models can stem from insufficient density of reference observed data, resulting in an inability to capture fine-scale climate signals (Kyselý \& Plavcová 2010, Rauscher et al. 2010), and can also be artificially amplified by the lack of a rain gauge correction in the observations, especially in the winter (Adam \& Lettenmaier 2003, Yang et al. 2005).

The other effects of higher resolution on simulated precipitation include larger spatial variability and inter-annual variability (IAV), and better resolved fine-scale precipitation structures corresponding more closely with observations (Jaeger et al. 2008, Rauscher et al. 2010). The evaluation of RCM simulations over the Alpine region also showed that the error characteristics of precipitation can worsen when analyzed on smaller scales (subdomains), while for air temperature, error characteristics remain similar to those of a larger evaluation region (Suklitsch et al. 2011).

Although air temperature characteristics are usually improved in high-resolution simulations, RCMs often simulate a summer climate that is too dry and warm in southeastern Europe when driven by both reanalysis (Hagemann et al. 2004) and GCM (Jacob et al. 2007). These errors have been attributed to deficiencies in land surface parameterizations as well as systematic errors in the dynamics (Hagemann et al. 2004). Some features of temperature biases over Europe may depend on the ability of RCMs to properly capture the atmospheric circulation (Sanchez-
Gomez et al. 2009, Kjellström et al. 2011, Plavcová \& Kyselý 2011). In addition, most RCMs also overestimate summer temperature IAV in central, eastern and southeastern Europe (Jacob et al. 2007, Lenderink et al. 2007, Vidale et al. 2007).

The forthcoming Fifth Assessment Report of the Intergovernmental Panel on Climate Change will present new findings on a regional climate change that, among other things, will be built on a set of regional climate model simulations prepared within the Coordinated Regional Downscaling Experiment (CORDEX, see Giorgi et al. 2009 for more information). For Europe, many of those simulations will be performed at a very high resolution of $\sim 10 \mathrm{~km}$ to provide new insight into local climate and its possible future evolution. In the region of central and eastern Europe (CEE) a similar effort, with emphasis on climate change impacts and assessment of vulnerability, has already been carried out within 2 recent projects of the European Commission's 6th Framework Programme (FP6): CECILIA (Central and Eastern Europe Climate Change Impact and Vulnerability Assessment, www.cecilia-eu.org) and CLAVIER (Climate Change and Variability: Impact on Central and Eastern Europe, www.clavier-eu.org). In both projects, one of the key objectives was to deliver information on climate change in the region of CEE by means of RCM simulations at a very high resolution of $10 \mathrm{~km}$ (see Halenka 2008 and Jacob et al. 2008 for more details).

The present study focuses on testing the ability of CECILIA RCMs to capture the main features of the climate in CEE for the period 1961-1990. For this purpose, the RCMs were driven by European Centre for Medium-Range Weather Forecasts (ECMWF) ERA-40 reanalyses (Uppala et al. 2005), and the results were validated against the E-OBS version 6.0 gridded dataset of station observations (Haylock et al. 2008). Our goal was to evaluate the gain obtained by using a high resolution over a small domain in comparison to a lower resolution $(25 \mathrm{~km})$ over a larger domain as in the FP6 ENSEMBLES project (ENSEMBLE-based Predictions of Climate Changes and their Impacts, www.ensembles-eu.org, see van der Linden \& Mitchell 2009 for more details).

\section{DATA AND ANALYSIS METHODS}

We used the results prepared by 5 CECILIA teams from the following institutions: Czech Hydrometeorological Institute (CHMI), Czech Republic; Charles University in Prague (CUNI), Czech Republic; Eötvös 
Loránd University (ELU), Hungary; Hungarian Meteorological Service (OMSZ), Hungary; and National Meteorological Administration (NMA), Romania. These teams employed 4 regional climate models: 2 versions of ALADIN-Climate (Farda et al. 2010) and 2 versions of RegCM3 (Pal et al. 2007).

The two versions of ALADIN-Climate correspond to cycles 24 and 28 of the ARPEGE/IFS code. Their physical parameterizations are different. While the original version of ALADIN-Climate (cycle 24) developed by Météo-France has a physical parameterization package derived directly from the one used in GCM ARPEGE-CLIMAT 4 (Déqué 2007), the other version, ALADIN-Climate/CZ (cycle 28), is based on the numerical weather prediction version of the ALADIN model in operational use at CHMI in 2002 and 2003. The major differences in the Czech version include new radiation and planetary boundary layer process schemes, different cloudiness and largescale precipitation schemes and improved deep convection and gravity wave drag schemes with the parameterization of mountain blocking and lift effects based on mean orography. For more detailed information on both ALADIN-Climate versions, we refer to Farda et al. (2010).

The two versions of RegCM3 differ in some aspects of the physical parameterizations, one in the original setting described by Pal et al. (2007), named alpha for distinction, and the other, called beta, with applied changes in large-scale precipitation schemes. The modifications in the beta version were motivated by a large bias of precipitation found during sensitivity tests conducted with the RegCM3 alpha model over the Carpathian Basin (Torma et al. 2008) and included a decrease in the cloud-to-rain autoconversion rate by half, increasing the raindrop evaporation rate coefficient by a factor of 50 and reducing the raindrop accretion rate by half. More information on the applied changes and their justification can be found in Torma et al. $(2008,2011)$.

The spatial resolution of the CECILIA simulations was $10 \mathrm{~km}$, and the integration period, after excluding a necessary spin-up period (year 1960 for most models, years 1958-1960 for ALADIN-Climate), covered the years 1961-1990. All models were driven by ECMWF ERA-40 reanalyses, either directly or via a double-nesting technique. The latter means that the model is first driven by ECMWF ERA-40 reanalyses in a coarser resolution (e.g. $50 \mathrm{~km}$ ) over a larger geographical domain, and then the resulting simulation is taken to drive the same model again but in the finer spatial resolution mode (10 $\mathrm{km}$ in this case), hence covering a smaller integration domain. ALADIN-
Climate/CZ and RegCM3 alpha of the CUNI team were the only models where the double nesting was employed, with driving RCM simulations having a horizontal resolution of either 50 (ALADIN-Climate/ CZ) or $25 \mathrm{~km}$ (RegCM3 alpha) and originally coming from the FP6 project ENSEMBLES. An overview of CECILIA teams, their models, integration domains and driving data is given in Table 1 . Some parameterization settings of the CECILIA models are in Table 2. The integration domains are also shown in Fig. 1.

Except for the CECILIA RCMs, we also considered the data from 5 models involved in the FP6 project ENSEMBLES that run their RCMs at a resolution of about $25 \mathrm{~km}$ over the common integration domain covering all of Europe (Christensen et al. 2010). This was done to enable the comparison of the very high resolution CECILIA RCMs data with those of ENSEMBLES and possibly identify benefits of running RCMs in a configuration of the CECILIA experiments. The overview of ENSEMBLES teams/models is also in Table 1. Three of 5 ENSEMBLES RCMs were selected because of their use in both projects, thus allowing a comparison of RCM qualities in different configurations. The remaining 2 RCMs (HIRHAM5 model of the Danish Meteorological Institute, Denmark, and CLM 2.4.6 model of the Swiss Federal Institute of Technology Zurich, Switzerland) were chosen because the relevant teams (but not RCMs) were also involved in the CECILIA project.

The investigation of model performance was based on a comparison of simulated properties of seasonal mean air temperature and seasonal sum of precipitation against observations represented by the E-OBS dataset. The validation was carried out over areas of the selected CEE countries (Austria, Czech Republic, Hungary, Romania and Slovakia), each country separately, for the period 1961-1990. The detailed listing of RCMs and individual countries covered within their integration domains is in Table 1. Before the validation, we first transformed the RCM data from their native grids to the regular $0.25^{\circ}$ latitude-longitude grid of the E-OBS dataset. Transformation was done in 2 steps. First, a bilinear interpolation was used to remap the data on the regular $0.125^{\circ}$ latitudelongitude grid, and then we averaged four $0.125^{\circ}$ grid points to the final resolution. The same procedure was applied on the orography, and the resulting difference between the model and E-OBS orography was multiplied by the climatological temperature lapse rate $\left(-6.5 \mathrm{~K} \mathrm{~km}^{-1}\right)$ to correct the $\mathrm{RCM}$ air temperature data.

For each season and country, we derived 19611990 climatology mean fields of air temperature (or 
Table 1. CECILIA and ENSEMBLES partners, regional climate models (RCMs), settings and central and eastern European countries where RCM performance is tested (domain size in points and number of vertical levels). $\mathrm{A}=\mathrm{Austria}$; $\mathrm{BG}=\mathrm{Bulgaria}$; CHMI = Czech Hydrometeorological Institute, Czech Republic; CNRM = Centre National de Recherches Météorologiques, France; $\mathrm{CUNI}=$ Charles University in Prague, Czech Republic; CZ = Czech Republic; DMI = Danish Meteorological Institute, Denmark; ELU = Eötvös Loránd University, Hungary; ETH = Swiss Federal Institute of Technology Zurich, Switzerland; H = Hungary; ICTP = International Centre for Theoretical Physics, Italy; NMA = National Meteorological Administration, Romania; OMSZ = Hungarian Meteorological Service, Hungary; RO = Romania; SK = Slovakia

\begin{tabular}{|c|c|c|c|c|c|c|}
\hline Partner & Model & Acronym & $\begin{array}{l}\text { Resolution } \\
\quad(\mathrm{km})\end{array}$ & Domain size & $\begin{array}{l}\text { Boundary } \\
\text { forcing }\end{array}$ & Analyzed area \\
\hline \multicolumn{7}{|c|}{ CECILIA } \\
\hline CUNI & RegCM3 alpha & $\mathrm{Ra}$ & 10 & $184 \times 164 \times 23$ & ERA40 RegCM3@25 & $\mathrm{A}, \mathrm{CZ}, \mathrm{H}, \mathrm{SK}$ \\
\hline CHMI & ALADIN-Climate/CZ & $\mathrm{Az}$ & 10 & $160 \times 102 \times 43$ & $\begin{array}{c}\text { ERA 40 } \\
\text { ALADIN-Climate/CZ@50 }\end{array}$ & $\mathrm{A}, \mathrm{CZ}, \mathrm{H}, \mathrm{SK}$ \\
\hline NMA & RegCM3 alpha & Ra2 & 10 & $156 \times 102 \times 18$ & ERA 40 & $\mathrm{RO}, \mathrm{SK}$ \\
\hline OMSZ & ALADIN-Climate & $\mathrm{A}$ & 10 & $108 \times 72 \times 31$ & ERA 40 & $\mathrm{H}, \mathrm{SK}$ \\
\hline ELU & RegCM3 beta & $\mathrm{Rb}$ & 10 & $120 \times 100 \times 18$ & ERA 40 & $\mathrm{H}, \mathrm{SK}$ \\
\hline \multicolumn{7}{|c|}{ ENSEMBLES } \\
\hline CHMI & ALADIN-Climate/CZ & $\mathrm{Az}$ & 25 & $183 \times 205 \times 31$ & ERA 40 & $\mathrm{~A}, \mathrm{CZ}, \mathrm{H}, \mathrm{RO}, \mathrm{SK}$ \\
\hline CNRM & ALADIN-Climate & $\mathrm{A}$ & 25 & $229 \times 229 \times 31$ & ERA 40 & $\mathrm{~A}, \mathrm{CZ}, \mathrm{H}, \mathrm{RO}, \mathrm{SK}$ \\
\hline DMI & HIRHAM5 & $\mathrm{H}$ & 25 & $194 \times 210 \times 19$ & ERA 40 & $\mathrm{~A}, \mathrm{CZ}, \mathrm{H}, \mathrm{RO}, \mathrm{SK}$ \\
\hline ETHZ & CLM 2.4.6 & $\mathrm{C}$ & 25 & $193 \times 201 \times 32$ & ERA 40 & $\mathrm{~A}, \mathrm{CZ}, \mathrm{H}, \mathrm{RO}, \mathrm{SK}$ \\
\hline ICTP & RegCM3 alpha & $\mathrm{Ra}$ & 25 & $190 \times 206 \times 18$ & ERA 40 & $\mathrm{~A}, \mathrm{CZ}, \mathrm{H}, \mathrm{RO}, \mathrm{SK}$ \\
\hline
\end{tabular}

Table 2. Physical parameterization settings for the CECILIA regional climate models. NIMH = National Institute of Meteorology and Hydrology, Bulgaria; other partner names defined in Table 1

\begin{tabular}{|lcccccc|}
\hline Partner & Model & Numeric & $\begin{array}{c}\text { Vertical } \\
\text { coordinate }\end{array}$ & $\begin{array}{c}\text { Radiation } \\
\text { scheme }\end{array}$ & $\begin{array}{c}\text { Convection } \\
\text { scheme }\end{array}$ & $\begin{array}{c}\text { Surface } \\
\text { scheme }\end{array}$ \\
\hline CUNI & RegCM3alpha & Difference & Sigma & CCM3 & Grell (Fritch \& Chappell) & BATS \\
CHMI & ALADIN-Climate/CZ & Spectral & Hybrid & ACRANEB & Bougeault & ISBA \\
NMA & RegCM3 alpha & Difference & Sigma & CCM3 & Grell (Fritch \& Chappell) & BATS \\
NIMH & ALADIN-Climate & Spectral & Hybrid & FMR & Bougeault & ISBA \\
OMSZ & ALADIN-Climate & Spectral & Hybrid & FMR & Bougeault \\
ELU & RegCM3 beta & Difference & Sigma & CCM3 & Grell (Fritch \& Chappell) & BATS \\
\hline
\end{tabular}

precipitation) and analyzed their spatial variability and spatial correlation (between simulated and observed fields). We also determined a systematic error (bias) and averaged it over the territory of the country to gain a single characteristic. To assess RCM simulations from a temporal aspect, we studied the IAV of area-averaged seasonal mean air temperature (or sum of precipitation) within the 1961-1990 period. Standard deviations of time series consisting of 30 seasons (29 for winter) for a model $\left(\sigma_{T M}\right)$ and observations $\left(\sigma_{T O}\right)$ were calculated, and their ratio $\left(\sigma_{T M} / \sigma_{T O}\right)$ was used as a benchmark of the IAV of air temperature. For precipitation, we used the coefficient of variation (a ratio between standard deviation and mean). To study the spatial variability of climatology mean fields, we used either the standard deviation or again the coefficient of variation (only for precipitation).

\section{RESULTS}

\subsection{Air temperature}

The area-averaged systematic error (bias) of longterm seasonal temperature for the CECILIA and ENSEMBLES models, as well as for the ERA-40 driving data over CEE countries, is summarized in Table 3. The statistically significant bias, identified using the $t$-test of time series of yearly bias values, is highlighted in bold in Table 3 . The systematic errors of the CECILIA models are usually within the $\pm 1^{\circ} \mathrm{C}$ range, with cold bias dominating. Significant cold bias is detected in 3 out of 4 seasons (winter, spring, autumn) in the ALADIN-Climate (A) simulation and in spring in the ALADIN-Climate/CZ (Az) and CUNI RegCM3 alpha (Ra) simulations. Significant warm 


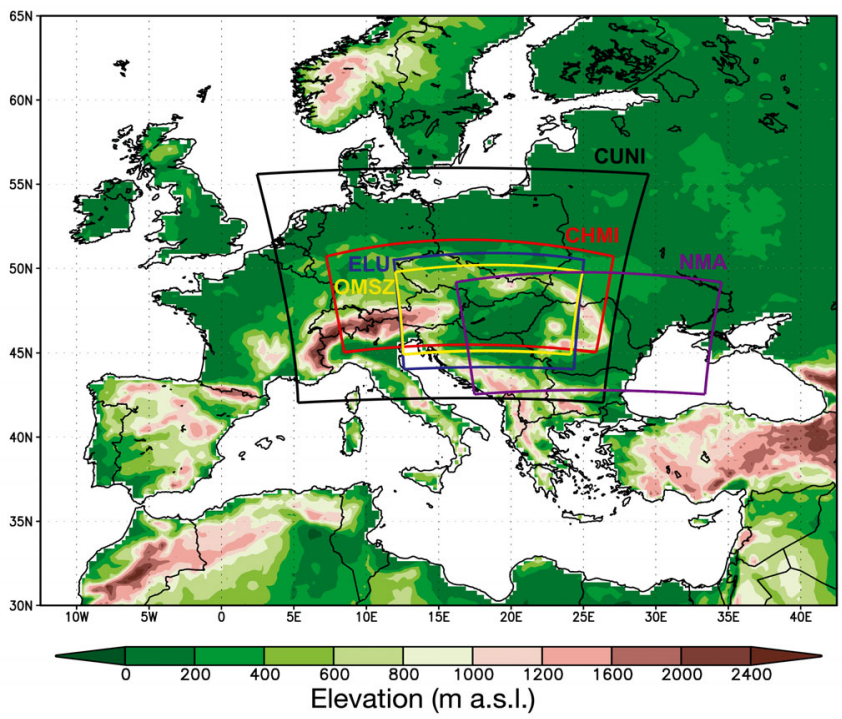

Fig. 1. E-OBS orography in $0.25^{\circ}$ spatial resolution with integration domains of the CECILIA regional climate models a.s.l. = above sea level biases of summer temperature detected in southeastern Europe by earlier studies (e.g. Hagemann et al. 2004) are present in some ENSEMBLES RCMs but not in the CECILIA RCMs. When the same models are compared, systematic errors of the CECILIA RCMs are usually smaller in magnitude than in the ENSEMBLES simulations. The only exception is ALADIN-Climate (A), whose systematic errors in the CECILIA experiment are always 1.5-3 K lower than those in the ENSEMBLES simulation, thus making it too cold in most seasons and often worse than the other ENSEMBLES RCMs.

The spatial variability of air temperature and its spatial correlation with observations are summarized in Fig. S1 (in the Supplement at www.int-res.com/ articles/suppl/c060p001_supp.pdf) in the form of a Taylor diagram (Taylor 2001). The CECILIA RCMs mostly show comparable or slightly better spatial correlations with observations than the ENSEMBLES models, often higher than $90 \%$. The RegCM3 alpha

Table 3. Bias of seasonal temperature in the CECILIA and ENSEMBLES models over central and eastern European countries for the 1961-1990 period. Bold: statistically significant bias. DJF = winter, MAM = spring, JJA $=$ summer, SON = autumn. Further abbreviations in Table 1

\begin{tabular}{|c|c|c|c|c|c|c|c|c|c|c|c|c|}
\hline \multirow{3}{*}{ Country } & \multirow{3}{*}{ Season } & \multicolumn{11}{|c|}{ Air temperature bias $\left({ }^{\circ} \mathrm{C}\right)$} \\
\hline & & \multicolumn{5}{|c|}{ CECILIA models } & \multicolumn{5}{|c|}{ ENSEMBLES models } & \multirow{2}{*}{ ERA40 } \\
\hline & & $\mathrm{Az}$ & $\mathrm{Ra}$ & $\mathrm{Rb}$ & Ra2 & $\mathrm{A}$ & $\mathrm{Az}$ & A & $\mathrm{H}$ & $\mathrm{C}$ & $\mathrm{Ra}$ & \\
\hline \multirow{4}{*}{ Austria } & DJF & -0.3 & -0.2 & & & & -0.5 & 0.1 & -0.9 & -1.1 & -1.1 & 0.2 \\
\hline & MAM & -1.3 & -1.1 & & & & -1.7 & 0.9 & -0.5 & -1.3 & -1.5 & 1.4 \\
\hline & JJA & -0.6 & -0.9 & & & & -0.8 & 1.6 & 0.3 & 0.2 & -0.6 & 1.8 \\
\hline & SON & -0.7 & -0.7 & & & & -1.1 & -1.0 & 0.0 & -0.8 & -1.3 & 0.6 \\
\hline \multirow{4}{*}{$\begin{array}{c}\text { Czech } \\
\text { Republic }\end{array}$} & DJF & 0.1 & 0.2 & & & & -0.2 & 0.9 & -1.0 & -0.1 & -0.7 & 0.6 \\
\hline & MAM & -0.8 & -0.6 & & & & -1.1 & 1.1 & 0.3 & 0.1 & -1.0 & 0.8 \\
\hline & JJA & 0.2 & -0.8 & & & & 0.3 & 1.5 & 0.8 & 1.2 & -0.1 & 0.8 \\
\hline & $\mathrm{SON}$ & 0.4 & 0.0 & & & & 0.2 & -0.6 & 0.5 & 0.2 & -0.6 & 0.7 \\
\hline \multirow{4}{*}{ Hungary } & DJF & 0.0 & 0.5 & 1.3 & & -0.9 & -0.4 & 0.7 & -0.8 & 0.0 & -0.6 & 0.2 \\
\hline & MAM & -1.3 & -1.2 & -0.5 & & -2.2 & -1.6 & 0.5 & 0.4 & 0.1 & -1.4 & 0.2 \\
\hline & JJA & 1.0 & -0.8 & -0.5 & & -0.6 & 1.2 & 2.3 & 1.5 & 2.7 & 0.2 & 0.0 \\
\hline & $\mathrm{SON}$ & 0.9 & -0.4 & 0.0 & & -2.6 & 0.6 & -0.9 & 0.6 & 0.3 & -1.0 & 0.4 \\
\hline \multirow{4}{*}{ Romania } & DJF & & & & 1.3 & & 0.2 & 0.6 & 0.0 & 0.4 & -0.5 & 0.4 \\
\hline & MAM & & & & -0.3 & & -1.7 & -0.4 & 0.6 & 0.4 & -1.3 & 0.4 \\
\hline & JJA & & & & -1.0 & & 0.2 & 1.1 & 1.4 & 2.5 & 0.0 & 0.5 \\
\hline & $\mathrm{SON}$ & & & & -0.4 & & 0.0 & -1.8 & 0.4 & 0.3 & -1.4 & 0.3 \\
\hline \multirow{4}{*}{ Slovakia } & DJF & 0.3 & 0.0 & 0.9 & 1.2 & -0.9 & 0.1 & 1.1 & -1.0 & -0.1 & -1.0 & 0.7 \\
\hline & MA M & -1.2 & -1.0 & -0.4 & 0.2 & -2.2 & -1.5 & 0.6 & 0.1 & -0.1 & -1.3 & 1.0 \\
\hline & JJA & 0.6 & -0.7 & -0.2 & 0.0 & -0.2 & 0.7 & 1.9 & 1.1 & 1.7 & 0.1 & 1.4 \\
\hline & $\mathrm{SON}$ & 0.4 & -0.3 & 0.0 & 0.4 & -2.3 & 0.2 & -0.6 & 0.4 & 0.2 & -0.9 & 2.1 \\
\hline & -3 & $\frac{1}{-2}$ & & & \begin{tabular}{l|l} 
& 1 \\
-0.5
\end{tabular} & $\mathrm{as}^{+0 .}$ & & $\frac{1}{+1}$ & + & & $\square$ & \\
\hline
\end{tabular}


(Ra2) simulation of NMA is the only exception to the previous, with slightly lowered correlations over Romania and Slovakia compared to the ENSEMBLES RCMs. Spatial variability of the CECILIA RCMs is mostly within the $0.8-1.2$ range of the observed spatial variability $(=1)$, and there is no systematic improvement in the CECILIA simulations as in the case of biases or spatial correlations. However, the CECILIA RCMs are within the range of spatial variability of the ENSEMBLES RCMs. Agreement of the simulated spatial characteristics with observations is the worst in Hungary, where the simulations substantially overestimate spatial variability in all seasons except winter.

The IAV of the CECILIA and ENSEMBLES models as well as the ERA-40 driving data over CEE countries is summarized in Table 4. In transient seasons (spring, autumn), the IAV of the CECILIA RCMs is often within the 0.9-1.1 range of the observed IAV (= 1). The only exception is the CUNI RegCM3 alpha (Ra) simulation that exhibits increased IAV in spring.
In winter, the CECILIA RCMs, except CUNI RegCM3 alpha (Ra), show decreased IAV (IAV ratio 0.4-0.9), with models of the ALADIN family being worse than RegCM3 models. An overestimation of summer temperature IAV in CEE reported by earlier studies (Jacob et al. 2007, Lenderink et al. 2007, Vidale et al. 2007 ) is present in all ENSEMBLES RCMs, but in only some CECILIA RCMs, namely ALADIN-Climate/CZ (Az) and RegCM3 alpha (Ra) of CUNI. When all seasons are considered, IAV is mostly captured better in the CECILIA than ENSEMBLES models.

\subsection{Precipitation}

The area-averaged systematic error (bias) of longterm seasonal precipitation sums over CEE countries for the CECILIA and ENSEMBLES models and their driving ERA-40 data is summarized in Table 5. The statistically significant bias, detected by the same cri-

Table 4. Inter-annual variability of seasonal temperature in the CECILIA and ENSEMBLES models expressed as a relative fraction of observed inter-annual standard deviation over central and eastern European countries for the 1961-1990 period. $\mathrm{DJF}=$ winter, $\mathrm{MAM}=$ spring, $\mathrm{JJA}=$ summer, $\mathrm{SON}=$ autumn

\begin{tabular}{|c|c|c|c|c|c|c|c|c|c|c|c|c|}
\hline \multirow{3}{*}{ Country } & \multirow{3}{*}{ Season } & \multicolumn{11}{|c|}{ Inter-annual standard deviation ratio } \\
\hline & & \multicolumn{5}{|c|}{ CECILIA models } & \multicolumn{5}{|c|}{ ENSEMBLES models } & \multirow{2}{*}{ ERA40 } \\
\hline & & $\mathrm{Az}$ & $\mathrm{Ra}$ & $\mathrm{Rb}$ & $\mathrm{Ra} 2$ & $\mathrm{~A}$ & $\mathrm{Az}$ & A & $\mathrm{H}$ & $\mathrm{C}$ & $\mathrm{Ra}$ & \\
\hline \multirow{4}{*}{ Austria } & DJF & 0.51 & 1.16 & & & & 0.52 & 0.59 & 1.18 & 1.03 & 1.20 & 1.00 \\
\hline & MAM & 0.89 & 1.34 & & & & 0.96 & 1.11 & 1.27 & 1.20 & 1.45 & 0.92 \\
\hline & JJA & 1.29 & 1.38 & & & & 1.25 & 1.69 & 1.78 & 1.66 & 1.60 & 0.91 \\
\hline & $\mathrm{SON}$ & 0.91 & 1.06 & & & & 0.93 & 0.85 & 1.27 & 1.11 & 1.13 & 1.00 \\
\hline \multirow{4}{*}{$\begin{array}{c}\text { Czech } \\
\text { Republic }\end{array}$} & DJF & 0.54 & 1.11 & & & & 0.57 & 0.61 & 1.26 & 1.01 & 1.16 & 1.03 \\
\hline & MAM & 1.08 & 1.36 & & & & 1.20 & 1.30 & 1.36 & 1.16 & 1.52 & 0.98 \\
\hline & JJA & 1.20 & 1.01 & & & & 1.29 & 1.56 & 1.39 & 1.77 & 1.32 & 0.96 \\
\hline & $\mathrm{SON}$ & 0.99 & 1.01 & & & & 1.04 & 0.96 & 1.26 & 1.18 & 1.11 & 0.98 \\
\hline \multirow{4}{*}{ Hungary } & DJF & 0.48 & 1.01 & 0.77 & & 0.63 & 0.49 & 0.69 & 1.13 & 0.89 & 1.06 & 0.94 \\
\hline & MAM & 1.08 & 1.19 & 1.05 & & 1.06 & 1.24 & 1.27 & 1.18 & 1.16 & 1.39 & 0.95 \\
\hline & JJA & 2.00 & 2.13 & 1.02 & & 1.27 & 1.93 & 2.47 & 1.92 & 2.19 & 1.89 & 1.07 \\
\hline & $\mathrm{SON}$ & 1.07 & 0.95 & 1.05 & & 1.07 & 1.13 & 1.02 & 1.17 & 1.03 & 1.00 & 1.06 \\
\hline \multirow{4}{*}{ Romania } & DJF & & & & 0.80 & & 0.50 & 0.61 & 0.96 & 0.85 & 1.01 & 0.97 \\
\hline & MAM & & & & 0.98 & & 1.02 & 1.02 & 1.08 & 1.07 & 1.14 & 0.95 \\
\hline & JJA & & & & 1.29 & & 1.43 & 1.71 & 1.88 & 2.12 & 1.58 & 1.02 \\
\hline & $\mathrm{SON}$ & & & & 1.05 & & 1.24 & 0.78 & 1.13 & 1.22 & 1.09 & 1.01 \\
\hline \multirow{4}{*}{ Slovakia } & DJF & 0.45 & 1.08 & 0.82 & 0.85 & 0.66 & 0.45 & 0.59 & 1.11 & 0.95 & 1.13 & 1.02 \\
\hline & MAM & 0.98 & 1.24 & 1.03 & 1.01 & 0.94 & 1.07 & 1.17 & 1.20 & 1.09 & 1.40 & 0.96 \\
\hline & JJA & 1.36 & 1.32 & 1.00 & 1.02 & 1.04 & 1.48 & 1.87 & 1.57 & 1.98 & 1.53 & 1.03 \\
\hline & $\mathrm{SON}$ & 0.98 & 0.90 & 0.97 & 0.88 & 0.89 & 1.02 & 0.88 & 1.11 & 1.05 & 0.96 & 0.95 \\
\hline \multicolumn{13}{|c|}{\begin{tabular}{|l|l} 
& \\
\end{tabular}} \\
\hline 0 & 0.5 & \multicolumn{2}{|c|}{0.75} & \multicolumn{2}{|c|}{0.9} & 1.1 & \multicolumn{2}{|c|}{1.25} & 1.5 & & 2 & 3 \\
\hline
\end{tabular}


terion as for air temperature, is again highlighted in bold in Table 5. The CECILIA RCMs simulate more precipitation than is observed. The excess of seasonal precipitation is smaller $(<\sim 50 \%)$ for ALADIN-Climate/CZ (Az) and RegCM3 beta (Rb) models, whereas RegCM3 alpha (Ra, Ra2) models overestimate precipitation in all seasons, sometimes by more than $100 \%$. ALADIN-Climate (A) models capture winter and autumn precipitation very well but double seasonal precipitation sums in spring and summer. The CECILIA RCMs generate higher (and less realistic in the majority of cases) seasonal sums of precipitation than their relevant ENSEMBLES counterparts or the ENSEMBLES models in general. Dry summer conditions in southeastern Europe detected in RCM simulations by earlier studies (e.g. Hagemann et al. 2004, Jacob et al. 2008) are partly present in some ENSEMBLES RCMs but not in the CECILIA RCMs.

Spatial variability of precipitation and its spatial correlation with observations is again summarized in the form of a Taylor diagram in Fig. S2 in the Supplement. Spatial correlations with observed precipitation vary strongly among the CECILIA models (and the ENSEMBLES models), seasons and assessed areas. For example, the spatial correlation of the CUNI RegCM3 alpha (Ra) summer precipitation in Hungary is only $28 \%$, but over neighboring Slovakia, it reaches $87 \%$. RegCM3 beta $(\mathrm{Rb})$ is the only model where improvements prevail when compared to its ENSEMBLES counterpart (International Centre for Theoretical Physics, Italy, RegCM3 alpha, Ra). For other CECILIA RCMs, we detect worsening of a different magnitude or no significant changes in any direction. However, in general, all CECILIA RCMs are within the range of spatial correlations of the ENSEMBLES models.

Spatial variability of the precipitation field, when accessed by a standard deviation ratio as in the Tay-

Table 5. Bias of seasonal precipitation in the CECILIA and ENSEMBLES models over central and eastern European countries for the 1961-1990 period. Bold: statistically significant bias. DJF = winter, MAM = spring, JJA = summer, $\mathrm{SON}=$ autumn

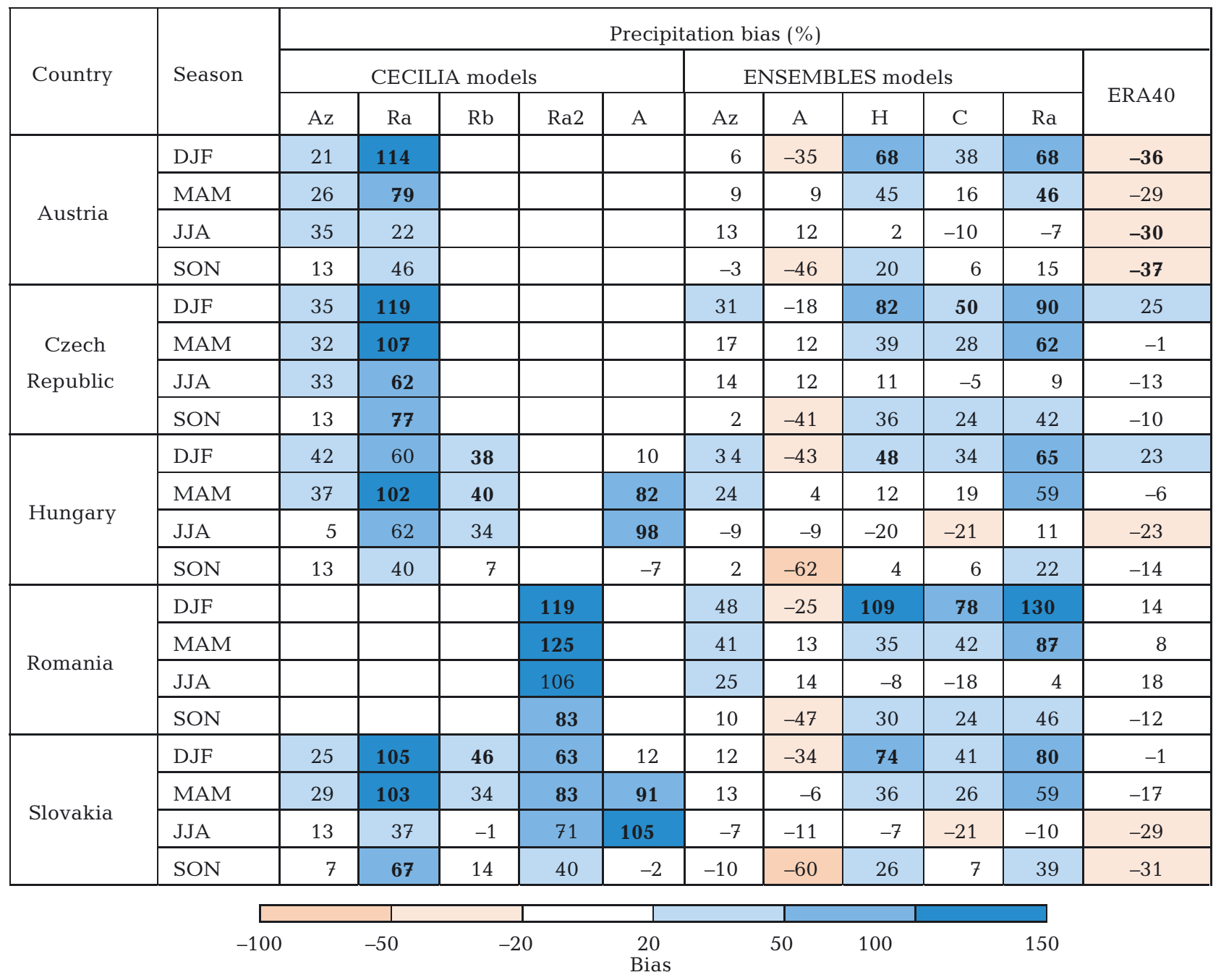


lor diagram, is mostly larger in the CECILIA RCMs than in their ENSEMBLES counterparts and is also larger than in observations, especially in countries with complex topography (all except Hungary). This is mainly in the ALADIN-Climate (A) and both RegCM3 alpha (Ra, Ra2) models. On the other hand, RegCM3 beta $(\mathrm{Rb})$ shows unchanged or even reduced spatial variability of precipitation, and ALADIN-Climate/CZ (Az) shows changes in both directions that seem to be partly related to the height of orography over the country. When the spatial variability of the precipitation field is assessed by using a coefficient of variation ratio to rule out the effect of precipitation bias, all CECILIA RCMs (even those with significant wet biases) show spatial variability close to the observed one (not shown). Their spatial variability, when the same models are compared, is mostly slightly reduced and worse but, in general, is still very close to that of the ENSEMBLES models (not shown).
The IAV of area-averaged precipitation is described by the coefficient of variation ratio (model to observation) and is presented in Table 6. With values predominantly in the $0.5-0.9$ range of the observed $\operatorname{IAV}(=1)$, the CECILIA RCMs tend to underestimate precipitation IAV. ALADIN-Climate/CZ (Az) has the best agreement with the observed IAV from all CECILIA RCMs. NMA RegCM3 alpha (Ra2) substantially overestimates summer precipitation IAV. It is also the only CECILIA RCM where IAV is increased compared to its ENSEMBLES counterpart. For other CECILIA RCMs, we rather see the opposite, i.e. a reduction of precipitation IAV. In seasons when precipitation IAV is lessened in the ERA-40 driving data, we also find smaller IAV in CECILIA (and some ENSEMBLES) RCMs. Otherwise, there is no noticeable feature in simulated precipitation IAV like that in air temperature. When all seasons, countries and models are considered, the capture of IAV is similar or slightly worse in the CECILIA models compared with ENSEMBLES models.

Table 6. Inter-annual variability of seasonal precipitation in the CECILIA and ENSEMBLES models expressed as relative fraction of observed inter-annual coefficient of variation over central and eastern European countries for the 1961-1990 period. $\mathrm{DJF}=$ winter, $\mathrm{MAM}=$ spring, $\mathrm{JJA}=$ summer, $\mathrm{SON}=$ autumn

\begin{tabular}{|c|c|c|c|c|c|c|c|c|c|c|c|c|}
\hline \multirow[t]{3}{*}{ Country } & \multirow[t]{3}{*}{ Season } & \multicolumn{11}{|c|}{ Inter-annual coefficient of variation ratio } \\
\hline & & \multicolumn{5}{|c|}{ CECILIA models } & \multicolumn{5}{|c|}{ ENSEMBLES models } & \multirow[t]{2}{*}{ ERA40 } \\
\hline & & $\mathrm{Az}$ & $\mathrm{Ra}$ & $\mathrm{Rb}$ & $\mathrm{Ra} 2$ & $\mathrm{~A}$ & $\mathrm{Az}$ & $\mathrm{A}$ & $\mathrm{H}$ & $\mathrm{C}$ & $\mathrm{Ra}$ & \\
\hline \multirow{4}{*}{ Austria } & DJF & 0.92 & 0.85 & & & & 0.86 & 1.75 & 0.82 & 0.81 & 0.82 & 0.92 \\
\hline & MAM & 0.68 & 0.58 & & & & 0.70 & 0.80 & 0.84 & 0.64 & 0.65 & 0.76 \\
\hline & JJA & 0.72 & 0.79 & & & & 0.84 & 0.71 & 1.56 & 1.10 & 1.18 & 1.06 \\
\hline & $\mathrm{SON}$ & 1.14 & 1.08 & & & & 1.19 & 1.63 & 1.10 & 1.24 & 1.23 & 1.06 \\
\hline \multirow{4}{*}{$\begin{array}{c}\text { Czech } \\
\text { Republic }\end{array}$} & DJF & 0.86 & 0.70 & & & & 0.89 & 1.26 & 0.72 & 0.80 & 0.72 & 0.79 \\
\hline & MAM & 0.84 & 0.48 & & & & 0.84 & 1.18 & 1.25 & 0.94 & 0.76 & 0.85 \\
\hline & JJA & 0.86 & 0.56 & & & & 0.93 & 0.68 & 1.04 & 1.17 & 0.84 & 0.87 \\
\hline & SON & 1.25 & 0.91 & & & & 1.45 & 1.29 & 0.93 & 1.15 & 1.15 & 1.09 \\
\hline \multirow{4}{*}{ Hungary } & DJF & 0.87 & 0.61 & 0.74 & & 0.87 & 0.89 & 1.48 & 0.78 & 0.69 & 0.66 & 0.66 \\
\hline & MAM & 0.74 & 0.62 & 0.76 & & 0.69 & 0.81 & 1.11 & 1.09 & 0.93 & 0.87 & 1.02 \\
\hline & JJA & 1.08 & 1.05 & 0.88 & & 0.67 & 0.97 & 1.02 & 1.15 & 1.01 & 1.16 & 1.18 \\
\hline & SON & 0.80 & 0.83 & 0.88 & & 0.87 & 0.89 & 1.25 & 0.79 & 0.91 & 0.92 & 0.98 \\
\hline \multirow{4}{*}{ Romania } & DJF & & & & 0.68 & & 1.02 & 1.05 & 0.81 & 0.81 & 0.74 & 0.71 \\
\hline & MAM & & & & 0.98 & & 0.81 & 0.87 & 0.97 & 1.05 & 0.88 & 1.03 \\
\hline & JJA & & & & 1.53 & & 0.93 & 0.91 & 1.78 & 1.59 & 1.28 & 1.25 \\
\hline & $\mathrm{SON}$ & & & & 1.01 & & 0.98 & 1.27 & 0.74 & 0.95 & 0.69 & 1.05 \\
\hline \multirow{4}{*}{ Slovakia } & DJF & 1.07 & 0.67 & 0.80 & 0.77 & 0.87 & 0.99 & 1.50 & 0.86 & 0.82 & 0.71 & 0.73 \\
\hline & MAM & 1.02 & 0.84 & 1.00 & 1.11 & 0.74 & 1.03 & 1.14 & 1.28 & 0.99 & 1.06 & 0.93 \\
\hline & JJA & 0.98 & 0.80 & 0.87 & 1.40 & 0.64 & 1.07 & 0.97 & 1.00 & 1.07 & 1.02 & 1.23 \\
\hline & SON & 0.97 & 0.79 & 0.83 & 0.87 & 0.78 & 1.03 & 1.23 & 0.83 & 0.91 & 0.84 & 1.32 \\
\hline & 0 & 0.5 & 0.75 & Coe & ient of & $\begin{array}{r}1 . \\
\text { ariatic }\end{array}$ & ratio & 1.25 & 1. & & 2 & \\
\hline
\end{tabular}




\section{DISCUSSION}

Analysis of the CECILIA RCM simulations reveals that the models are able to capture the main features of the climate in CEE. We find both improvement and degradation of climate description provided by the high-resolution CECILIA simulations on small domains compared to the lower resolution ENSEMBLES simulations on a larger domain.

Although the assessed quality of the CECILIA and ENSEMBLES simulations is often similar, we see the majority of CECILIA simulations improve on ENSEMBLES simulations for air temperature characteristics. The biases are usually reduced, and the warm anomaly of summer temperature in southeastern Europe reported by earlier studies (e.g. Hagemann et al. 2004) is not present in the CECILIA RCMs. However, the decrease of warm summer air temperature bias is accompanied by a larger wet precipitation bias in all CECILIA RCMs except ALADIN-Climate/ $\mathrm{CZ}(\mathrm{Az})$. Therefore, the better score for the CECILIA RCMs in simulated summer air temperature could be a consequence of their tendency to simulate excessive precipitation amounts. The increased summer temperature IAV described by other authors (Jacob et al. 2007, Lenderink et al. 2007, Vidale et al. 2007) is present in only some CECILIA simulations. The significant feature of simulated IAV is its underestimate in the ALADIN family models in winter. Referring to the results of Sanchez-Gomez et al. (2009), we suggest that this may be caused by underestimating the mean persistence of anticyclonic weather regime episodes, which bring cold arctic air from the north and east to CEE. Suppressing the episodes of the cold weather could also be reflected in relatively small cold (or even warm) biases of winter temperature in the affected simulations. The spatial pattern of seasonal air temperature is well captured in all simulations, and further improved by the CECILIA RCMs. A slightly worse score over Hungary is rather a consequence of comparing relatively smooth spatial temperature fields, where even a small difference between a model and observations can deteriorate spatial variability or correlation.

The CECILIA RCMs show clear worsening in simulated properties of precipitation. Similarly, as in previous studies (e.g. Jaeger et al. 2008, Rauscher et al. 2010), we detect larger precipitation amounts (compared to ENSEMBLES RCMs) and significant wet biases in all high-resolution CECILIA simulations. Spatial properties of the precipitation field as well as the IAV of precipitation are also less realistic in some regions and $\mathrm{RCMs}$, although some minor improvements can be detected as well. Our investigation suggests that the results and possible gain (or loss) from the CECILIA experiments over the ENSEMBLES models are strongly dependent on which particular simulation is assessed. Because of the variety of models and their different settings, we cannot unambiguously identify the reasons explaining the performance of the CECILIA RCMs. We suspect that 3 major effects play important roles.

First, some physical parameterizations of RCMs can be sensitive on different scales of spatial resolution, and they can require further adaptation before models are run at a very high resolution of $10 \mathrm{~km}$. All CECILIA teams employing the RegCM3 model detected significant wet biases regardless of other factors, e.g. coupling with the ERA-40 data or domain setting. This led to the development of the new version of the RegCM3 model (here referred to as the beta version) with adjusted parameters of the largescale precipitation scheme that has reduced the precipitation bias and improved other properties of simulated precipitation (Georgescu et al. 2009) as well as air temperature (Torma et al. 2008, 2011). The decrease in the precipitation bias with the RegCM3 beta version is shown here in the results of the ELU team $(\mathrm{Rb})$, but it was also reported later by CUNI and NMA teams (M. Belda, M. Caian pers. comm.). However, in this study, we present only original CUNI and NMA RegCM3 alpha (Ra, Ra2) simulations that are available on the project public data archive. Fragmentation of the ALADIN-Climate/CZ (Az) simulated precipitation field (Fig. 2) in central Europe, which is strong in winter and reflected in very low spatial correlation with observations in this season, also points out some weak points in the model physics. We suspect that an imperfection in the horizontal diffusion of humidity in the model may be a source of the fragmentation of the simulated precipitation in both the CECILIA and ENSEMBLES experiments, but this hypothesis must still be investigated further.

Second, coupling of the relatively coarse ERA-40 data with an RCM of $10 \mathrm{~km}$ spatial resolution over a small domain could limit the ability of the RCM to produce high-resolution features, and deteriorate results because of the proximity of the coupling zone to the inner part of the domain. This could be further amplified by the presence of mountain ranges on the domain boundary. CECILIA ALADIN-Climate (A) simulation was driven directly by ERA-40 reanalyses over a small domain with mountains on its edges. Following the results of earlier studies by Csima \& Horányi (2008) and mainly Farda et al. (2010), who studied the 

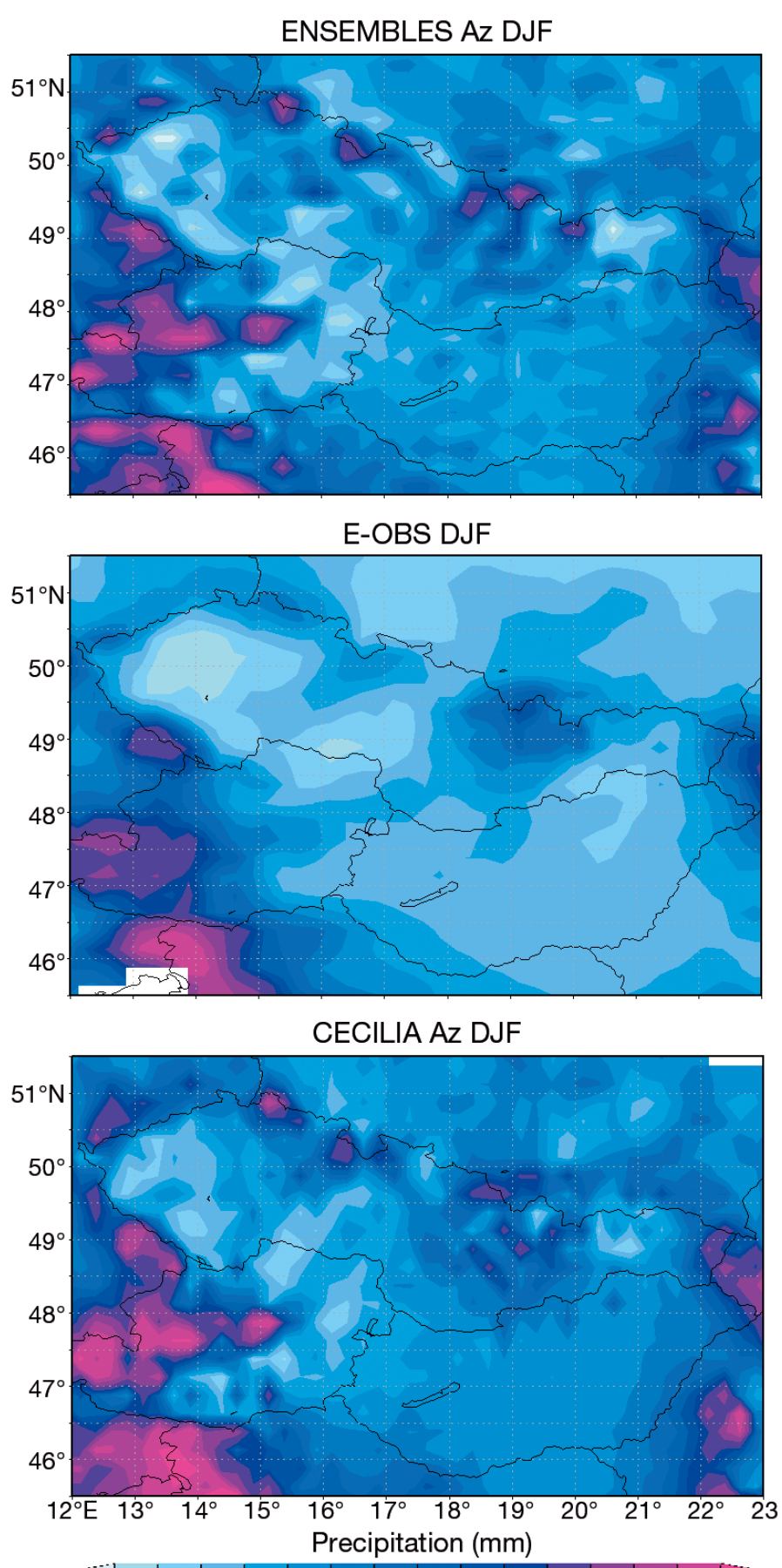

507090110130150170190210230250300350400500

Fig. 2. Comparison of winter (DJF) mean precipitation sums over central Europe in the E-OBS gridded observation dataset (middle) and 2 ALADIN-Climate/CZ (Az) simulations from the ENSEMBLES (left) and CECILIA (right) projects

effect of domain size on the quality of ALADINClimate simulations over Bulgaria, we hypothesize that high deviations of CECILIA ALADIN-Climate (A) simulations from observations are at least partly caused by the setting of the integration domain. In CECILIA ALADIN-Climate (A) simulations, the integration domain and its coupling zone are perhaps too small compared to the resolution of the ERA-40 driving data, and there is a risk of imbalance between spatial and temporal resolution of the coupling zone. Especially fast-travelling synoptic systems could enter the domain's interior without being captured properly by a coupling procedure working with $6 \mathrm{~h}$ frequency. In the case of RegCM3 alpha (Ra, Ra2) models, the excessive precipitation could be associated with not only an internal model design (as discussed above) but also a domain setting. Sensitivity tests with RegCM3 models (not shown here) performed in the early stage of the CECILIA project showed a significant response of precipitation to the choice of the domain for the same model and configuration (CECILIA WP2 Deliverable D2.1 2008). The complex land cover, including a sea surface, within the integration domain of this CECILIA simulation (see Fig. 1) could affect simulated precipitation and air temperature, e.g. by forcing the model climate systematically towards predefined sea surface temperature.

Finally, properties of the E-OBS dataset could also affect validation results. The E-OBS dataset was developed in the framework of the ENSEMBLES project to enable validation of RCM simulations at 50 and $25 \mathrm{~km}$ resolution. The previous studies carried out over the Czech Republic detected low spatial variability of air temperature (Kyselý \& Plavcová 2010) and precipitation (Zíková et al. 2012) in the EOBS dataset. The highest deficiencies of E-OBS were detected mainly over mountain areas. The density of an underlying station network in the E-OBS dataset is one of the key factors affecting its properties and the consequent results of climate model validation (Kyselý \& Plavcová 2010, Rauscher et al. 2010). During preparation of this study, we detected an improvement in the validation of the CECILIA RCMs in central Europe when the E-OBS dataset version 6.0, based on a higher number of stations, was used instead of version 2.0 (not shown). Despite some recent updates, the density of station data available for EOBS still remains very low in many CEE countries, and needs to be further increased to enhance the suitability of the E-OBS dataset for the evaluation of high-resolution RCMs.

\section{CONCLUSIONS}

The aim of this paper was to evaluate 1961-1990 simulations of regional climate models at a high spa- 
tial resolution of $10 \mathrm{~km}$ over small integration domains, and identify their possible gain relative to simulations of a lower resolution $(25 \mathrm{~km})$, but carried out over larger integration domains. This was done by comparing 2 sets of RCM simulations from the FP6 CECILIA and FP6 ENSEMBLES projects with observations represented by the E-OBS dataset.

We found that the CECILIA models at $10 \mathrm{~km}$ resolution are capable of capturing the main features of recent climate in the target region of $\mathrm{CEE}$, and that they in many aspects reach similar or even better measures of quality as the lower resolution ENSEMBLES models. The major improvements are found in the properties of simulated air temperature. Still, we have detected several weaknesses. Compared with the ENSEMBLES simulations, the CECILIA experiments do not provide any significant gain in the quality of precipitation description and rather bring more drawbacks than improvements.

We suspect 3 major reasons for the worsening quality of simulated precipitation. (1) An internal design of some models, especially their package of physical parameterizations, is sensitive to a spatial scale at which the model is employed. (2) Coupling of the coarse ERA-40 data with an RCM over a small domain may limit the ability of the model to produce high-resolution features. In addition, the choice of the integration domain in some CECILIA simulations could cause a propagation of errors related to coupling into the interior of the integration domain and thus deteriorate the results. Finally, (3) one reason for the apparently worse performance of the CECILIA models can be associated with imperfections of the reference E-OBS dataset rather than the model simulations themselves. Testing the CECILIA models at the very high resolution of $10 \mathrm{~km}$ would perhaps require new, even more developed datasets of station observations than E-OBS, currently considered the best pan-European gridded station dataset.

Even though the CECILIA simulations show no overall but only partial improvement over the ENSEMBLES models, we believe it still makes sense to carry out similar experiments with high-resolution RCMs. Such experiments may better account for details not obvious from comparison with E-OBS, and also enhance topographic features important for climate impact studies. In addition, even high systematic errors in control climate simulations may not significantly affect the simulation of climate change as the analysis of CECILIA scenario simulations implies.

Using reanalysis-driven RCM simulations is a fruitful step for evaluating the role of resolution and domain design. The new ERA-Interim reanalysis at higher resolution will help to reduce the problem of a jump in resolution in the perfect boundary condition experiments. In the forthcoming CORDEX project (Giorgi et al. 2009), led by the World Climate Research Programme, the perfect boundary condition approach will be systematized.

Acknowledgements. We acknowledge the E-OBS dataset from the EU-FP6 project ENSEMBLES (http://ensembleseu.metoffice.com) and the data providers in the ECA\&D project (http://eca.knmi.nl). This study was performed within the CECILIA project, funded by the European Commission's 6th Framework Programme under contract number 037013. The authors also gratefully acknowledge the financial support of the following foundations and research programs: CzechGlobe Centre (CZ.1.05/1.1.00/02.0073) and projects CZ.1.07/2.4.00/31.0056 (Operational Programme of Education for Competitiveness of Ministry of Education, Youth and Sports of the Czech Republic) and P209/11/2405 (Czech Science Foundation). Partial support was also provided under the Research Plan of MSMT (No. MSM 0021620860) and through the COST 734 activity locally supported by MSMT grant OC10061.

\section{LITERATURE CITED}

Adam JC, Lettenmaier DP (2003) Adjustment of global gridded precipitation for systematic bias. J Geophys Res 108: 4257, doi:10.1029/2002JD002499

> Bergant K, Belda M, Halenka T (2007) Systematic errors in the simulation of European climate (1961-2000) with RegCM3 driven by NCEP/NCAR reanalysis. Int J Climatol 27:455-472

CECILIA (2008) D2.1: RCM simulations forced by observations. Accessed 10 Nov 2011. Available at www.ceciliaeu.org/restricted/deliverables.php

> Christensen JH, Kjellström E, Giorgi F, Lenderink G, Rummukainen M (2010) Weight assignment in regional climate models. Clim Res 44:179-194

Csima G, Horányi A (2008) Validation of the ALADINClimate model at the Hungarian Meteorological Service. Idöjárás 112:155-178

Déqué M (2007) Frequency of precipitation and temperature extremes over France in an anthropogenic scenario: model results and statistical correction according to observed values. Glob Planet Change 57:16-26

Farda A, Déqué M, Somot S, Horányi A, Spiridonov V, Tóth H (2010) Model ALADIN as regional climate model for Central and Eastern Europe. Stud Geophys Geod 54: 313-332

Georgescu F, Tascu S, Caian M, Banciu D (2009) A severe blizzard event in Romania - a case study. Nat Hazards Earth Syst Sci 9:623-634

Giorgi F, Mearns LO (1991) Approaches to regional climate change simulation: a review. Rev Geophys 29:191-216

Giorgi F, Mearns LO (1999) Introduction to special section: regional climate modeling revisited. J Geophys Res 104: 6335-6352

Giorgi F, Jones C, Asrar GR (2009) Addressing climate information needs at the regional level: the CORDEX framework. WMO Bulletin 58:175-183

Hagemann S, Machenhauer B, Jones R, Christensen OB, 
Déqué M, Jacob D, Vidale PL (2004) Evaluation of water and energy budgets in regional climate models applied over Europe. Clim Dyn 23:547-567

Halenka T (2008) Regional climate modeling activities in CECILIA project: introduction. Idöjárás 112:III-IX

Halenka T, Kalvová J, Chládová Z, Demeterová A, Zemánková K, Belda M (2006) On the capability of RegCM to capture extremes in long term regional climate simulation - comparison with the observations for Czech Republic. Theor Appl Climatol 86:125-145

Haylock MR, Hofstra N, Klein Tank AMG, Klok EJ, Jones PD, New M (2008) A European daily high-resolution gridded dataset of surface temperature and precipitation for 1950-2006. J Geophys Res 113:D20119, doi:10.1029/ 2008JD10201

Jacob D, Bärring L, Christensen OB, Christensen JH and others (2007) An inter-comparison of regional climate models for Europe: model performance in present-day climate. Clim Change 81:31-52

Jacob D, Kotova L, Lorenz P, Moseley Ch, Pfeifer S (2008) Regional climate modeling activities in relation to CLAVIER project. Idöjárás 112:141-153

> Jaeger EB, Anders I, Lüthi D, Rockel B, Schär C, Seneviratne S (2008) Analysis of ERA40-driven CLM simulations for Europe. Meteorol Z 17:349-367

Kjellström E, Nikulin G, Hansson U, Strandberg G, Ullerstig A (2011) 21st century changes in the European climate: uncertainties derived from an ensemble of regional climate model simulations. Tellus 63:24-40

Kyselý J, Plavcová E (2010) A critical remark on the applicability of E-OBS European gridded temperature data set for validating control climate simulations. J Geophys Res 115:D23118, doi:10.1029/2010JD014123

Laprise R (2008) Regional climate modelling. J Comput Phys 227:3641-3666

Lenderink G, van Ulden A, van den Hurk B, van Meijgaard E (2007) Summertime inter-annual temperature variability in an ensemble of regional climate model simulations: analysis of the surface energy budget. Clim Change 81:233-247

Meissner C, Schädler G, Panitz HJ, Feldmann H, Kottmeier C (2009) High-resolution sensitivity studies with the regional climate model COSMO-CLM. Meteorol Z 18: 543-557

Pal JS, Giorgi F, Bi X, Elguindi N and others (2007) Regional climate modeling for the developing world: the ICTP

Editorial responsibility: Filippo Giorgi,

Trieste, Italy
RegCM3 and RegCNET. Bull Am Meteorol Soc 88: 1395-1409

- Plavcová E, Kyselý J (2011) Evaluation of daily temperatures in Central Europe and their links to large-scale circulation in an ensembles of regional climate models. Tellus 63:763-781

Rauscher SA, Coppola E, Piani C, Giorgi F (2010) Resolution effects on regional climate model simulations of seasonal precipitation over Europe. Clim Dyn 35:685-711

$>$ Reichler T, Kim J (2008) How well do coupled models simulate today's climate? Bull Am Meteorol Soc 89:303-311

Sanchez-Gomez E, Somot S, Déqué M (2009) Ability of an ensemble of regional climate models to reproduce weather regimes over Europe-Atlantic during the period 1961-2000. Clim Dyn 33:723-736

Suklitsch M, Gobiet A, Truhetz H, Awan NK, Göttel H, Jacob D (2011) Error characteristics of high resolution regional climate models over the Alpine area. Clim Dyn 37:377-390

Taylor K (2001) Summarizing multiple aspects of model performance in a single diagram. J Geophys Res 106: 7183-7192

Torma C, Bartholy J, Pongrácz R, Barcza Z, Coppola E, Giorgi F (2008) Adaptation of the RegCM3 climate model for the Carpathian Basin. Idöjárás 112:233-247

Torma C, Coppola E, Giorgi F, Bartholy J, Pongrácz R (2011) Validation of a high-resolution version of the regional climate model RegCM3 over the Carpathian Basin. J Hydrometeorol 12:84-100

> Uppala SM, Kållberg PW, Simmons AJ, Andrae U and others (2005) The ERA-40 re-analysis. QJR Meteorol Soc 131:2961-3012

van der Linden P, Mitchell JFB (eds) (2009) ENSEMBLES: climate change and its impacts: summary of research and results from the ENSEMBLES project. Met Office Hadley Centre, Exeter

> Vidale PL, Lüthi D, Wegmann R, Schär C (2007) European summer climate variability in a heterogeneous multimodel ensemble. Clim Change 81:209-232

> Yang D, Kane D, Zhang Z, Legates D, Goodison B (2005) Bias correction of long-term (1973-2004) daily precipitation data over the northern regions. Geophys Res Lett 32: L19501, doi:10.1029/2005GL024057

Zíková N, Holtanová E, Kalvová J (2013) Annual precipitation cycle in regional climate models: the influence of horizontal resolution. Theor Appl Climatol. 112:521-533

Submitted: December 2, 2011; Accepted: November 11, 2013 Proofs received from author(s): April 25, 2014 